\title{
Composites of Electrochemically Reduced Graphene Oxide and Polythiophene and Their Application in Supercapacitors
}

\author{
F. Ibáñez-Marín ${ }^{2,3}$, C. Morales-Verdejo ${ }^{1}$, M.B. Camarada ${ }^{4, *}$ \\ ${ }^{1}$ Centro de Genómica y Bioinformática, Facultad de Ciencias Universidad Mayor, Santiago, Chile \\ ${ }^{2}$ Universidad Bernardo OHiggins, Departamento de Ciencias Químicas y Biológicas \& Escuela de \\ Kinesiología, General Gana 1702, Santiago, Chile. \\ ${ }^{3}$ Centro Integrativo de Biología y Química Aplicada (CIBQA), Universidad Bernardo OHiggins, \\ General Gana 1702, Santiago, Chile \\ ${ }^{4}$ Centro de Nanotecnología Aplicada, Facultad de Ciencias, Universidad Mayor, Chile \\ *E-mail: maria.camarada@umayor.cl
}

doi: $10.20964 / 2017.12 .54$

Received: 12 August 2017 / Accepted: 17 October 2017 / Published: 12 November 2017

Composite films consisting of polythiophene (PTh) and graphene oxide (GO) were synthetized by electrochemical polymerization. Consequently, the GO was reduced via cyclic voltammetry to form a reduced composite (PTh/rGO), which presented higher conductivity than PTh. Specific capacitance values were calculated from galvanostatic charge-discharge profiles. At a current density of $0.5 \mathrm{~A} \cdot \mathrm{g}^{-1}$, the specific capacitance of PTh/rGO presented a good value $\left(318 \mathrm{~A} \cdot \mathrm{g}^{-1}\right)$. However, its behavior was distant from a typical supercapacitor, indicative of a low reversibility during the charge-discharge processes and poor capability as supercapacitor material. Moreover, its stability diminished considerably after repetitive cycling. Experimental conditions of synthesis of $\mathrm{PTh} / \mathrm{rGO}$ require to be optimized for the application of the composite as electrode material in supercapacitors.

Keywords: polythiophene, graphene oxide, supercapacitors

\section{$\underline{\text { FULL TEXT }}$}

(C) 2017 The Authors. Published by ESG (www.electrochemsci.org). This article is an open access article distributed under the terms and conditions of the Creative Commons Attribution license (http://creativecommons.org/licenses/by/4.0/). 